\title{
Mesoscale geomorphic change on barrier estuarine regime at the tropical coast of Chandipur, India: Evidence from assessment of grain-size distribution
}

Koushik Saha ( $\nabla$ koushiksaha09@gmail.com )

University of North Bengal https://orcid.org/0000-0003-2412-2478

SUBHAJIT SINHA

University of Calcutta

\section{Research Article}

Keywords: Marsh, Particle size distribution, Meso-scale behaviour, Compositional data, Multivariate statistics

Posted Date: January 14th, 2022

DOI: https://doi.org/10.21203/rs.3.rs-1163794/v1

License: (c) (i) This work is licensed under a Creative Commons Attribution 4.0 International License.

Read Full License 


\section{Abstract}

It is crucial for policy makers and environmental managers to determine the future dynamics of coastal wetlands, especially the existence of their response, disruption, and recovery regimes. Reconstruction of meso-scale evolution in coastal ecosystems can help to adapt coastal resource management techniques to the natural scales of system activity, thereby encouraging true biodiversity. This research provides an overview of decadal (mesoscale) geomorphic transition by high-resolution grain size analysis of a sediment deposit from a barrier estuary regime on the Chandipur coast, India. Coastal marshland's grain size distribution (GSD) has generally been analyzed using End Member Mixing Models (EMMA) and Probability Density Function (PDF) methods (e.g. log-normal, log skew-Laplace). Although these techniques do not consider the compositional nature of the records, which can undermine the outcomes of the interpretation of sedimentary deposits. The approach to reliable granulometric analysis of lithostratigraphic sequences aims at establishing direct links between fluid dynamics and subsequent shifts in the texture of sediments. In this study, GSD analysis of marsh sediment is represented by compositional data analysis (CoDa) and a multivariate statistical framework. Barrier estuary evolution, presented by time lapses of satellite maps coupled with grain size and carbon content of marsh sediment, primarily reflects the evolving hydrodynamics of the back barrier area. These findings will provide a statistically robust analysis of the depositional system in coastal marshland. Multiannual environmental variations in the back barrier configuration illustrate the importance of this applied approach with respect to bridging the basis of estuarine evolution and process information.

\section{Introduction}

Estuaries and their surrounding habitats of coastal ecosystems will be exposed to a number of stressors in the coming years which might make them vulnerable (Barbier et al., 2011; Brevik and Homburg, 2004; Nordstrom et al., 2018). Modern estuarine ecosystems can be threatened by a variety of stressors, such as climate change, sea level changes, and increasing human interventions over the decades ahead, and these may affect their functions and resource value. In the immediate term, the establishment of future estuary trajectories is of vital importance for a broad community of organizations and environmental managers (Creel, 2003; Oost et al., 2012; Seager and Vecchi, 2010). Barrier systems occupy about $15 \%$ of the coastline of the world and are better developed along micro-tidal coasts (tidal range $<2 \mathrm{~m}$ ), with the majority being connected to low-lying coastal plains and river deltas (FitzGerald et al., 2008; Pilkey et al., 2009; Stutz and Pilkey, 2011). Many natural salt marshes are formed on the leeward side of the barrier islands, which help to protect coastal ecosystems and human growth from increasing sea levels and storms (Leonardi et al., 2018; He et al., 2012). They are commonly considered to be efficient coastal stabilizers (Möller, 2006; Gedan et al., 2011) and do have the capacity to sequester carbon from the atmosphere (Mcleod et al., 2011). Development and sustainability in the salt marshes are controlled by the allogenic sediment input and in-situ vegetation's effect on the sedimentation process itself (Fagherazzi et al., 2012; Pethick, 1981; Van Wijnen and Bakker, 2001). Also, these marshes are particularly sensitive to shifts in hydromorphological regime, for instance, triggered by rising sea levels and increased 
catastrophic events (Morris et al., 2002; Mudd et al., 2004; Reed, 1995). Subsequent sea level rises, which are intimately linked to glacio-isostatic modification or tectonic movement (Shennan et al., 2006), also play an important role in morphodynamic evolution and govern the transgressive presence of Barrier ecosystems (Roy, 1994). The wave built, shore parallel accumulation of the Barrier bar in Chandipur is separated from the mainland by mudflats and saltmarsh. The purpose of this research is to evaluate the long-term expansion of the tidal back barrier salt marsh on the Odisha coast of the Bay of Bengal in order to get a better understanding of how sediment dynamics have evolved over time.

The geomorphology of the estuary environments of the Holocene barrier is commonly well understood in terms of subsequent sediment dynamics and landform evolution over the macroscale (centuries to millennia), as well as on the microscale (seconds to years) (Clarke et al., 2014a; Ladd et al., 2019; Molinaroli et al., 2009). In this respect, intermediate mesoscale (years-decades-centuries) 'behavior' remains unclear and has become a crucial time scale of concern (Cooper and McKenna, 2008; Cooper et al., 2007; Cooper, 2013; Cooper et al., 2018; Jennings et al., 1993; Orford et al., 1995). In addition, enhancing our limited knowledge of system behavior on a meso-scale has been described more generally as a hurdle in coastal geomorphology (French and Burningham, 2009; French et al., 2016). Evidence of system resilience over the meso-scale is very difficult to obtain, since direct physical demonstrations of robust behaviour in coastal settings, particularly at the mesoscale, are quite uncommon (Klein and Nicholls, 1999; Klein et al., 1998). Many scholars have focused on high-resolution study of sedimentary records in recent years in order to enrich historical records (French and Burningham, 2009; Kanhaiya et al., 2017; Sathish et al., 2018). Numerical modelling has been used to understand the vertical growth and evolution of marsh by minerogenic and organogenic sedimentation under relative sea level rise from the Severn Estuary, southwest Britain by Allen, 1990b; Allen, 1992; Fagherazzi et al., 2012. Analysis of particle size in estuarine environments has also successfully identified historical variation in deposition processes (Allen and Haslett, 2002; Allen, 2004; Allen and Haslett, 2006; Dark and Allen, 2005; Lecce and Pavlowsky, 2004; Stupples and Plater, 2007; Saha and Sinha, 2021; Su et al., 2016). Several researchers successfully applied high-resolution particle size measurement as a proxy for mesoscale hydrodynamic variability in an estuary barrier system (Clarke et al., 2014a; Lario et al., 2002; Spencer et al., 1998; Switzer et al., 2005). It is obvious that the grain-sizes of a depositional system are controlled by the effectiveness of environmental discrimination to a large extent, but study on grain size using a robust statistical approach is largely elusive on the Indian coast. Multivariate statistics have been used as an environmental discriminator for characterizing and testing the efficacy of grain-size analysis (Alsharhan and El-Sammak, 2004; Purkait and Majumdar, 2014; Zubillaga and Edwards, 2005).

Geoscientists have created geomorphic facies models of most sedimentary environments in order to recognize their deposits in the geological record, which has largely led to the geomorphic approach (Heap et al., 2004; Walker, 1992). The cross-sectional lithofacies information recognizes different lithological components of the deposit with their associated sedimentary structures, biological characteristics. For a one-dimensional view of down-hole data, applying stratigraphic architecture to certain sedimentary settings involves some methodological limitations (Houben, 2007). As a result, reliance on sedimentary facies analysis in subsurface settings poses a significant challenge. By evaluating compositional data 
analysis associated with a multivariate statistical approach, some researchers provide a methodological framework for studying sedimentary facies using grain size variation (Flood et al., 2015; Puy et al., 2018; Tang et al., 2018). This study examines how the Chandipur coast's back barrier marsh (after classification by Allen, 2000) has evolved over time. It also investigates how sediment delivery mechanisms and sedimentation rates in mature salt marshes have evolved over time. Particle size analysis will be used to distinguish between different sedimentary environments in the back barrier regime of Chandipur. By providing a statistically robust approach to particle size analysis, we hope to advance our understanding of the evolution of mature salt marshes. Compositional data analysis (CoDa) and a multivariate statistical framework will help us better understand how Chandipur salt marshes change over time.

\section{Materials And Methods 2.1 Study area:}

The coastal areas of Chandipur, in the Balasore district of Orissa, border the mainland with the open ocean, the Bay of Bengal. The current study was conducted in Chandipur, close to the Buribalam River confluence. A wide intertidal flat, a narrow siliciclastic beach, and a coast-parallel sandy barrier with a back barrier marsh characterize Chandipur's coastal region. Barrier bars developed along these coastal areas are backed by coastal wetlands. Chandipur marsh forms a grassy fringe on the back side of the barrier formed near the mouth of the Buribalam River (Fig. 1). This coastal area has a moist and temperate climate. Meteorological data for the Chandipur region of Balasore was acquired from the Balasore district town's meteorological station. Throughout the monsoon season, relative humidity is high, and it declines during the winter season (Supplementary Fig. 1). The average daily precipitation data follows a similar trend, with an annual precipitation total of about $1900 \mathrm{~mm}$. Using the 2000-2018 datasets, wind graphs illustrating average wind frequency (\%), velocities $\left(\mathrm{m} \mathrm{s}^{-1}\right)$, and direction for the coastal area of Balasore, Orissa, India were generated. Using the open-air-R program, wind charts were created to study seasonal variations in wind characteristics based on data from the Balasore station. The wind database indicates a strong south-westerly wind direction throughout the summer monsoon season (Supplementary Fig. 2). The surface zonal wind speed increases during the rainy season in the middle of the year, when the maximum speed reaches $5-6 \mathrm{~m} / \mathrm{s}$. The surface primary wave direction of the Wavewatch-III dataset for the Bay of Bengal shows that the SW-NE directional wave is dominant for most of the season in this area (Supplementary Fig. 3A). The swell height of these surface waves becomes 3 to 5 meters high during this time (Supplementary Fig. 3B). The siliciclastic coastal region contains a gently sloping topography and a mesotidal environment with a semidiurnal tidal range (Chakrabarti 2005; Mukherjee et al. 1987). The morphology of this wetland illustrates that it is predominantly covered by low-lying small plants that transit into the ripple-laminated tidal flat (Supplementary Fig. 4). The western side of this marshland, showing relatively denser vegetation and with higher elevation, is part of the high marsh area. This marsh is distinguished by a variety of flora, including Porteresia coarctata, Suaeda 
nudiflora, Suaeda maritime, and Acanthus ilicifolius. The lower marshy region is characterized by a Porteresia coarctata population with heights of up to 50-60 cm (Supplementary Fig. 4).

\subsection{Study of marshland with aerial image analysis}

Google Earth TM (GE) has been used in various studies of river networks, glacial, marine, landslides, and desert landforms (Cooper, 2013; Goudie, 2013; Liang et al., 2018). The marsh in the back of Barrier Island, as well as the direction of the waves and winds, are depicted using oblique aerial photograph of the Chandipur coast. (Fig. 2). The Google Earth Engine is a cloud-based engine that provides easy access to massive geographic data collections (Chen et al., 2017). This study made use of multi-date, multi-year Landsat time-series data from the barrier estuary regime of Chandipur during the last two decades, from 2000 to 2018. In the Animation file 1, the outputs of these observations are represented as a.gif file, which contains the animation data.

\subsection{Sampling across the marsh and subsurface sampling}

In the field, we noticed that the eastern side of the marshland was higher than the eastern side. As a consequence, one $\mathrm{E}-\mathrm{W}$ directed transect (C- transect) was conducted for study to cover the sample from lower marsh to higher marsh. Sediment samples were taken from the top $1 \mathrm{~cm}$ of surface sediments. We measured the elevation using the simplest method proposed by Emery (1961). Elevation differences along a profile were measured by surveying some closely spaced locations with two people. The elevation from zero to 1.4 meters as a function of distance is recorded in the $C$ transect. Systematic sampling was carried out at ninety places, beginning at C-1 in the western section and ending at C-90 in the higher eastern region, with an interval of about $10 \mathrm{~m}$. A subsurface trench sample (CT) was taken from the upper, more stable section of this wetland at height of $1.2 \mathrm{~m}$ (Figure 1).

\subsection{Sample analysis and statistical computations:}

\subsubsection{Particle size analysis using laser granulometer}

Sediment samples are processed in compliance with conventional laboratory procedures (e.g. Carver, 1971; Chang et al., 2007). Prior to grain size measurements, $\sim 0.5 \mathrm{~g}$ of dry bulk sample was sequentially pretreated to remove organic material, carbonate and clay minerals from the samples as follows:

(1) In small beakers, samples were dissolved in $5 \mathrm{~mL}$ of $30 \%$ hydrogen peroxide $\left(\mathrm{H}_{2} \mathrm{O}_{2}\right)$ solution to extract organic materials.

(2) Then carbonates were extracted with $5 \mathrm{~mL}$ of $10 \%$ hydrochloric acid $(\mathrm{HCl})$.

(3) After that, the processed samples were cleaned at least twice with deionized water until the decanted water is clear. The sample solution was then blended with distilled water and set over to stay overnight. It was then washed until the decanted water is clear. 
(4) Through adding a sufficient amount of dispersing agent sodium hexametaphosphate solution $\left[\left(\mathrm{NaPO}_{3}\right)_{6}\right]$, the samples were distributed in an ultrasonic bath.

Finally, these samples were analyzed on a Partica mini LA-350, Horiba Scientific laser granulometer following pretreatment. All measurements were carried out at the laboratory of the University of North Bengal, Darjeeling, India. The laser granulometer measured the percentages of various particle sizes in a variety of size classes from $0 \Phi$ to $16 \Phi$.

\subsubsection{Organic Carbon content measurement using loss of ignition (LOI)}

Total organic carbon determination is a measurement of one of the chemical components of organic matter that is commonly used to indicate the presence of organic matter in sediment. The Loss on ignition (LOI) approach is a semi-quantitative method for determining organic materials. By heating the samples consecutively in a muffle furnace, the weight percent organic matter and carbonate content of sediments may be measured using LOI (Bengtsson \& Enell, 1986). The measurement of organic carbon content is critical in palaeoclimatology, and the most often used technique, loss on ignition, is utilized for the calculation utilizing the methods of Heiri et al., 2001.

\subsubsection{Examination of contour plots}

In this study, the particle-size distributions (PSDs) are plotted as contoured surface plots. The advantage over traditional plotting approaches is that the whole PSD is shown, allowing for the recognition of subtle textural patterns and various modes (Beierle et al., 2002).

\subsubsection{Multivariate Statistics with coefficients from the log- normal and log skew-Laplace distributions}

Over the past century, various models for the observed mass size distribution of sediments have been proposed. The most frequently used model is Krumbein's log-normal distribution (Krumbein and Pettijohn, 1938; Friedman, 1962). Bagnold and Barndorff-Nielsen (1980) argued that the continuing usage of this distribution was based on the inertia of tradition. Among the advantages for the log-hyperbolic method include the increased sensitivity of parameter estimates in distinguishing between samples of varying but closely related origins, as well as their connection to physical processes like as erosion and deposition (Hartmann and Christiansen, 1992; McArthur, 1987; Sutherland and Lee, 1994). However, the loghyperbolic distribution cannot be fitted to bimodal distributions. However, another distribution, notably log skew Laplace, may be explored for environmental analysis from coastal sediments of grain size distribution data since it provides a concise and robust approach for classifying coastal sediments (Filler 1984, Fieller et al., 1992a). Thus, it is preferable to utilise the log skew Laplace distribution to comprehend the deposits of coastal settings. So, in this study we have used log-normal and log skew-Laplace methods for distinguishing similar sedimentary associations of the Chandipur marshland. When it comes to distinguishing sedimentary facies in coastal environments, these two methods have been proven to be effective by a number of researchers in the past. (Purkait and Majumdar, 2014; Robson et al., 1997). 
GSDs derived from the marsh samples in the form of closed data were investigated using PDFs with the log-normal and log skew-Laplace approaches.

The density function of the normal distribution is calculated as follows:

$$
g(X ; \mu, \sigma)=1 / \sigma \sqrt{2 \pi} \exp \left\{-1 / 2(X-\mu)^{2} / \mu^{2}\right\}
$$

Where $\sigma=$ standard deviation being $>0, \mu=$ mean size, and $x=$ observed variable, $\pi=3.143$ (constant). The log probability function appears to look like a parabola.

The skew-Laplace distribution can be written as:

$$
\begin{aligned}
g(X ; \alpha, \beta, \mu) & =(\alpha+\beta)^{-1} \exp \{(X-\mu) / \alpha\} \text { for } X \leq \mu \\
& =(\alpha+\beta)^{-1} \exp \{(\mu-X) / \beta\} \text { for } X>\mu
\end{aligned}
$$

where $\mathrm{x}$ reports observed variable, and $\mathrm{a}, \beta$ and $\mu$ are parameters as below:

$a=$ slope of left asymptote, i.e. coarser fractions

$\beta=$ slope of right asymptote, i.e. finer fractions

$\mu=$ point of intersection of two asymptotes.

The logarithm of Laplace distribution is graphically a set of intersecting lines. The difference between the values obtained from the two slopes, i.e., $(a \sim \beta)$ was used as an indicator of symmetry and used as a parameter (Purkait, 2002; Purkait and Majumdar, 2014). Although the log-normal and log-skew-Laplace are the limits of the log-hyperbolic family distributions, still we can't use the hyperbolic distribution in this analysis since most distributions are skewed (Barndorff-Nielsen, 1977; Christiansen and Hartmann, 1991). The log-normal and log skew-Laplace distribution coefficients were analyzed with PCA and cluster analysis to provide representations of grain size distribution of the dataset.

\subsubsection{Multivariate Statistics with Composition Data Analysis}

Nowadays, it appears important to reconsider sediment geochemical data from the perspective of compositional data analysis (Flood et al 2016; 2018 Buccianti et al., 2018). However, granulometric analysis has a very limited application; only a few studies from the Sundarban and Southeast China coasts have used this procedure (Flood et al., 2015; Tang et al., 2018). A composition is defined as a sample space for the normal unit $D$ simplex, $S^{D}$, consisting of a vector of $D$ positive elements adding up to a specified constant $k$, which is generally set to 1 (proportions) or 100 (percentages) by closure (Chayes, 1971). It establishes relationships between portions of a whole that include relative information i.e. ratios of size fractions and whose sample space is the simplex (Pawlowsky-Glahn and Egozcue, 2001).

$S^{D}=\left\{X=\left[X_{1}, X_{2} \ldots X_{D}\right] \mid X_{i}>0 ; \sum_{i=1}^{D} X_{i}=k\right\}$ 
Grain size data are a prominent example of compositional data (CoDa), which are vectors of positive components that represent portions of a total, and hence transmit solely relative information. When the relative weights of each size fraction are added together, they equal a constant (e.g. 100\%) in each sample, and any change in one fraction results in a change in the others. We used a centred logratio (clr) transformation (Aitchison 1986) to divide each studied variable by the geometric mean of all the size classes assessed, accompanied by a log transformation. GSD data is converted to the main log-ratio (clr) for closure effect and nonnormality by using the 'compositions' package in the R studio (current version 3.4.2). Following that, a matrix of 'loadings' is constructed using the PCA to indicate the degree to which each of the input GSDs fits each of the components. These loadings yield principal component scores, which are then used to compare the original data to the calculated principal components. The statistical package IBM SPSS Statistics version 24.0 used for PCA, hierarchical cluster analysis (HCA) and k-means cluster analysis on log transformed GSDs.

\subsubsection{Bivariant Plot}

Additionally, a bivariate diagram was plotted with mean grain size against sorting. The bivariate plot for subsurface samples purports to understand the depositional environment field, as defined by Tanner (1991a).

\section{Results And Interpretation}

\subsection{Surface and subsurface particle size distribution}

The surface contour plot of particle size distribution is plotted against different locations of the surface samples along the $\mathrm{C}$ transect according to distance from the initial sample location, $\mathrm{C} 1$, near Mean Sea Level of Chandipur. The surface contour plot of the particle size distribution on the surface sediments shows a gradual shifting of grain size towards a finer volumes towards the upper part of the marsh (Fig. 3A; lower C-1 to upper C-90). Notable coarse sediments are present at sample locations C-18 to C-20, close to the tidal flat, and the finest sediments are observed at locations $\mathrm{C}-83$ to $\mathrm{C}-85$, near the higher, vegetated area of the marshland. As seen in Fig. 3B, a more illustrative representation of up-trench patterns in saltmarsh deposits can be seen from the surface contour plots of grain size distribution (cf. Beierle et al., 2002; Clarke et al., 2014a; Donato et al., 2009; Rahman and Plater, 2014). Here, the volume percentage of the full range of laser granulometry-derived size fractions is given directly in relation to the trench depth. Overall fining of sediments is detected towards the top portion of this trench in this plot.

\section{INSERT FIG 3A\&3B}

\subsection{Multivariate statistics with log-normal \& log skew- Laplace coefficients with subsurface samples of marsh 3.4.1 PCA results with a log-normal and log skew-Laplace coefficients using Chandipur sediments}


Table 1 demonstrates the matrix association of lognormal coefficients used in the PCA from the subsurface samples of Chandipur. It shows a strong negative (c. -0.816) correlation between the mean and skewness. The PCA conducted on the data are illustrated in Table 2, where the $54.96 \%$ of the cumulative variance with a uniqueness of 2.19 is basically expressed by first main component. The second main component signifying just over $32.76 \%$ of residual cumulative variance has unique value of 1.31 . The cumulative expressed variation is $87.72 \%$ of the total variance. For the first and second main variable, scores tend to indicate dominant variation in mean and sorting respectively (Fig. 4A). The primary and second principal component loadings are shown in Fig. 5A \& 5B. Negative scores describe the general trend from the trench base to a depth of $87 \mathrm{~cm}$ for component 1, while the positive score defines the samples from $57 \mathrm{~cm}$ to the trench surface. So, the log-normal coefficients of subsurface samples also indicates a fining pattern in size distribution towards the top of the trench.

Table 1

Correlation matrix of log-normal coefficient of subsurface sediments of marshland.

\begin{tabular}{|lllll|}
\hline & Mean & Sorting & Skewness & Kurtosis \\
\hline Mean & 1 & & & \\
\hline Sorting & 0.048 & 1 & & \\
\hline Skewness & -0.816 & -0.275 & 1 & \\
\hline Kurtosis & 0.565 & -0.361 & -0.389 & 1 \\
\hline
\end{tabular}

Table 2

Total variance explained by the PCA on the lognormal coefficient from Chandipur trench samples.

\begin{tabular}{|llll|}
\hline Principal component & \multicolumn{3}{l|}{ Initial Eigenvalues } \\
\cline { 2 - 4 } & Total & \% of Variance & Cumulative \% \\
\hline 1 & 2.199 & 54.963 & 54.963 \\
\hline 2 & 1.31 & 32.762 & 87.724 \\
\hline 3 & 0.343 & 8.57 & 96.294 \\
\hline 4 & 0.148 & 3.706 & 100 \\
\hline
\end{tabular}

INSERT Table $1 \& 2$

INSERT FIG 4

INSERT FIG 5 
The coefficients like $\mu, a, \beta$ and sorting $\left(a^{2}+\beta^{2}\right)$ of log skew-Laplace distribution (Fieller et al., 1990) are used in PCA and cluster study. The values of a parameters are known to correspond to the coefficient of fine quality, with $\beta$ being the coarse coefficient, and $\mu$ as the modal size (Fieller et al., 1992b). The correlation matrix of log skew-Laplace coefficients utilised in the PCA is shown in Table 3 . There is a strong negative correlation present between $\mu$ and $\beta$ (c. -0.89) with a slightly lower negative correlation between $\alpha$ and $\beta$ along with $\mu$ and sorting at $c-0.675$ and c. -0.613 respectively. The model coefficients of $\mu$ with $\alpha$ and $\beta$ with sorting were found to be positively correlated at c. 0.727 and c. 0.841 respectively. The results of the PCA performed on the data are summarised in Table 4. The first principal component, with an eigenvalue of 3.016 , accounts for about 75.4 percent of the total variance. The second principal component, with a value of 0.825 , accounts for little more than $20.62 \%$ of the residual variance. For further analysis, the first and second main components were represented, involving a cumulative wattage of c. $96.03 \%$ of the variance. The two consecutive main component loadings are shown in Fig. 4B. The first principal component has the highest negative coefficients, relate to $\mu$ followed by $a$, with the remaining model coefficients having positive coefficient values. The positive coefficients shows that the second main component correspond to $\mu$ and $a$, while relating negatively to $\beta$.

Table 3

Correlation matrix of log-skew Laplace coefficient of subsurface sediments of Chandipur.

\begin{tabular}{|lllll|}
\hline & $\boldsymbol{\mu}$ & $\boldsymbol{\alpha}$ & $\boldsymbol{\beta}$ & Sorting \\
\hline $\boldsymbol{\mu}$ & 1 & & & \\
$\boldsymbol{\alpha}$ & 0.727 & 1 & & \\
$\boldsymbol{\beta}$ & -0.890 & -0.675 & 1 & \\
\hline Sorting & -0.613 & -0.202 & 0.841 & 1 \\
\hline
\end{tabular}

Table 4

Total variance explained by the PCA on the log-skew Laplace coefficient from Chandipur trench samples.

\begin{tabular}{|llll|}
\hline Principal component & \multicolumn{3}{l|}{ Initial Eigenvalues } \\
\cline { 2 - 4 } & Total & $\%$ of Variance & Cumulative \% \\
\hline 1 & 3.016 & 75.402 & 75.402 \\
\hline 2 & 0.825 & 20.626 & 96.029 \\
\hline 3 & 0.151 & 3.770 & 99.798 \\
\hline 4 & 0.008 & 0.202 & 100.000 \\
\hline
\end{tabular}

INSERT Table $3 \& 4$ 
Figure 5D \& 5E shows the first and second principle score component distributions from the PCA of the log skew-Laplace coefficients. For the first component, as shown in 5D, negative scores characterize the general trend from the surface of the trench to depth of $\mathrm{c} .56 \mathrm{~cm}$ indicative of $\beta$, and sorting while fluctuating variability is shown in the rest of the samples up to the base of the trench. The second main component scores seem to indicate the existence of and variability, with positive values up to $56 \mathrm{~cm}$ depth and relatively negative scores in the bottommost part.

\subsubsection{CA results with a log-normal and log skew-Laplace coefficients using Chandipur sediments}

The cluster analysis of the first and second principal component scores of the log-normal coefficients in Fig. 6A distinguishes four groups of facies. The relation between grain size and each of the sedimentary facies follows: (1) samples reflecting skews variability; (2) samples demonstrating heterogeneity in the sorting; (3) samples indicative of mean variability; (4) samples reflecting heterogeneity in kurtosis. There are minor variations in facies from the trench's surface to around $72 \mathrm{~cm}$ deep, but the dominant pattern is influenced by facies 1 and 2 . The composition of the cluster varies marginally from facies 1 to 3 , from 72 $\mathrm{cm}$ depth to $94 \mathrm{~cm}$ depth. In the lowest part, the member varies between facies 3and 4 only (Fig. 5C).

\section{INSERT FIG 6}

From the analysis of the two main PCA scores of the log skew-Laplace coefficients, total four groups of facies were obtained using clustering as shown in Fig. 6B. The grain size distribution associated with each sedimentary facies is as follows: (1) samples which reflect the variability of $\mu$; (2) variability of samples, without any coefficients of log skew-Laplace distribution; (3) samples indicative of $\beta$ and sorting variability; (4) samples indicative of a variability. From the base of the trench to a depth of c. 95 $\mathrm{cm}$ there are fluctuations between facies 3 and 4 . From c. $95 \mathrm{~cm}$ to c. $73 \mathrm{~cm}$, the samples consist of with the variability of samples from facies 1 to 3 . Finally, from c. $73 \mathrm{~cm}$ of the surface of the trench samples are composed of facies- 2 with few facies- 1 samples (Fig. 5F).

\subsection{Multivariate statistics with clr-transformed GSD data of marsh subsurface samples}

\subsubsection{PCA results from subsurface clr-transformed GSD data}

The subsurface samples are correlated with clr-transformed fractions of the grain size. The correlation matrix used in the PCA of clr-transformed GSDs are given in Table 5. In the matrix, positive relation between the fine sand to coarse silt and medium silt to very fine silt and clay is particularly noticeable. Table 6 summarizes the PCA performed on the clr-transformed data, where the first major component effectively represents $57.23 \%$ with a distinctiveness of $4.57 \%$. This is succeeded by the second component, which accounts for little more than 22.88 percent of the residual cumulative variance. The loadings from principal components are plotted in Fig. 7 and the coefficients indicate that the first main 
component relates positively to fractions of comparatively small size (coarse silt to very fine silt) and the other components correspond to coarse and medium silt. The sediment score distributions by using the PCA of the clr-transformed grain size data from the Chandipur marsh trench sample is shown in Fig. 5G \& $5 \mathrm{H}$. Component 1 shows an increasing trend towards the surface with negative scores near the trench base to a positive score at the top reflecting decreasing grain size (Fig. 5G). Other principal component scores show no dominant pattern, rather they show an overall prevalence of coarse to medium silt across the trench (Fig. $5 \mathrm{H})$.

Table 5

Correlation matrix of clr-transformed GSD for trench sediment of Chandipur marsh.

\begin{tabular}{|c|c|c|c|c|c|c|c|c|}
\hline & $1 \Phi-3 \Phi$ & $3 \Phi-4 \Phi$ & $4 \Phi-5 \Phi$ & $5 \Phi-6 \Phi$ & $6 \Phi-7 \Phi$ & $7 \Phi-8 \Phi$ & $8 \Phi-9 \Phi$ & $9 \Phi-11 \Phi$ \\
\hline $1 \Phi-3 \Phi$ & 1 & & & & & & & \\
\hline $3 \Phi-4 \Phi$ & -0.147 & 1 & & & & & & \\
\hline $4 \Phi-5 \Phi$ & -0.416 & 0.939 & 1 & & & & & \\
\hline $5 \Phi-6 \Phi$ & -0.344 & 0.421 & 0.6 & 1 & & & & \\
\hline $6 \Phi-7 \Phi$ & -0.274 & -0.652 & -0.488 & 0.264 & 1 & & & \\
\hline $7 \Phi-8 \Phi$ & -0.288 & -0.858 & -0.727 & -0.336 & 0.754 & 1 & & \\
\hline $8 \Phi-9 \Phi$ & -0.446 & -0.617 & -0.486 & -0.457 & 0.413 & 0.81 & 1 & \\
\hline $9 \Phi-11 \Phi$ & -0.228 & -0.753 & -0.647 & -0.521 & 0.362 & 0.764 & 0.639 & 1 \\
\hline
\end{tabular}

Table 6

Total variance explained by the PCA on the clr-transformed data from Chandipur.

\begin{tabular}{|llll|}
\hline Principal component & \multicolumn{3}{l|}{ Initial Eigenvalues } \\
\cline { 2 - 4 } & Total & $\%$ of Variance & Cumulative \% \\
\hline 1 & 4.57 & 57.23 & 57.23 \\
\hline 2 & 1.83 & 22.88 & 80.11 \\
\hline 3 & 1.12 & 14.01 & 94.12 \\
\hline 4 & 0.35 & 4.32 & 98.44 \\
\hline 5 & 0.10 & 1.19 & 99.64 \\
\hline 6 & 0.03 & 0.34 & 100 \\
\hline
\end{tabular}

INSERT Table $5 \& 6$

INSERT FIG 7 


\subsubsection{CA results from Chandipur subsurface clr-transformed GSD data}

Study of the cluster analysis suggests that there are four distinctive classes (Fig. 8) of sedimentary facies: (i) very fine silt with clay and colloid; (ii) coarse silt to fine silt; (iii) very fine to fine sand; (iv) medium to coarse sand. The deposits are considerably coarser from the trench's base to a depth of 87 $\mathrm{cm}$, exhibiting shifting trends between facies 3 and 4 (Fig. 5I). From there to sample CT-57, the cluster association varies between facies 2 to 4 . This fluctuating trend in cluster group association shows a resemblance with the PCA results. In the topmost part, i.e. from sample CT-57 to CT- 1 only facies 1 and 2 have been observed. The upward trend of these groups throughout the trench samples shows a fining-up sequence.

\subsection{Bivariate plot of mean grain size against sorting}

The bivariate logarithmic graph of mean vs sorting (phi $=\Phi ;$ Fig. 9 ) is plotted in relation to various depositional environment domains according to Friedman, 1967, Lario et al., 2002; Tanner, 1991b. This bivariate plot offers a legitimate way of reconstructing Holocene environmental change in coastal ecosystems where the development of barriers already has considerable influence over sediment deposition. While more extensive palaeoenvironmental details for the different marsh sites of Europe and America (i.e. Scotney, Guadalquivir, and Guadalete marsh) are available, the bivariate plot is an effective way of distinguishing between various depositional environments (Lario et al., 2002). The characteristics of these surface samples represent deposition environments near the transition between the environments of 'closed basin' and 'channel/fluvial and storm episodes', which falls into the 'partially open to restricted estuary'. Bivariate plots were designed to understand the changes in transportation regime reconstructed with the understanding of historical shifts in estuarine lagoon structure. The characteristics of these samples indicate that most sediments were deposited under 'partially open to restricted estuary' conditions (Fig. 9).

\section{INSERT FIG 9}

\subsection{Total Organic Carbon content of subsurface sediment}

Organic carbon ranged from $0.5-3.8 \%$ across all the subsurface samples (Fig. $5 \mathrm{~J}$ ). The lower part (bottom to $90 \mathrm{~cm}$ ) has a similar average TOC, with sediments ranging in-between $0.7-1.4 \%$, and the middle part ( $\sim 90$ to $\sim 55 \mathrm{~cm})$ has relatively high organic matter $(1.2-2.7 \%)$. The top most part $(\sim 55 \mathrm{~cm}$ to the surface) with the finer sedimentary unit of the deposit has the highest range of TOC values of the total trench with the highest organic matter (2.5-3.8\%).

\section{Discussion}




\subsection{Assessment of marsh growth in context of estuarine sediment dynamics}

Coastal sedimentation is a dynamic process characterised by cyclic fluctuation; GSDs accumulate as a result of the accumulation of sediment under highly variable conditions. A total of 117 samples from the CT location of the higher marsh region help us to distinguish different successions of sedimentary depositional environments, and the higher resolution of sampling enables these environments to be assessed more accurately. The contour plots of the particle size distribution of these trench samples indicate that sedimentary sequences have been fined up. The characteristics of an ancient sedimentary sequence of unknown origin may be compared to the known environments of present deposits along the CS transect (Fig. 3). Along the CS transect in the lower eastern part, the coarser grains are deposited in more open conditions where the tidal action is more significant. Conversely, in the northwest direction, finer grains are deposited in a rather tranquil state with lower energy. Thus, it may be possible to comprehend the depositional settings of older sedimentary sequences.

Additionally, we used multivariate statistics and CODA to analyze GSD facies in addition to qualitative descriptions and multivariate statistical analyses of PDF methods. Capturing the range of variation by dividing the information into dimensionally coherent components enables for the retention of total variance using the PCA technique. The decrease of dimensionality in a PDF technique is at the expense of total data variance, which may be addressed by utilising the entire GSD. There is a substantial number of variability in both the CA and PCA scores determined from the PDF coefficients in the lower zones. However, the Clr-transformed dataset reveals a consistent decline in the CA and PCA scores. This implies that the CA and PCA scores produced from the Clr-transformed dataset often result in a more advanced aggregation of textual and stratigraphic facies. Different GSD facies have been interpreted using upward trends in trench samples of saltmarsh, in conjunction with qualitative descriptions of GSD and multivariate statistical analysis. In this study, the results reveal three broad stratigraphical units inside the marsh deposit. From the bottom of the trench to the $\sim 90 \mathrm{~cm}$ the relatively coarser sediment has been deposited by allogenic inputs of mineral matter sediments might be settled as lag deposit. This deposition can be correlated with 'traction load,' a mixture of rolling and sliding particles through the bed, moving in a succession of fast hops, and the processes of 'surface creep' and 'saltation' reflect the 'coarse' portion of the deposited saltmarsh sediment. The mean grain size of sediment decreases in the sediment sequence within the depth of 90 to $55 \mathrm{~m} \mathrm{~cm}$ as the flow rate decreases, and this represents different mechanism of sediment transport and deposition linked to suspension, saltation, and bed creep loads that are affected by tidal ingress interaction. In the uppermost part of the saltmarsh trench, from $\sim 55 \mathrm{~cm}$ to the surface, the finer sedimentary unit accumulated as suspension load, where turbulent flow is necessary to retain 'fine' grain sizes within the water column. In the upper marsh, sediments are trapped by the salt marsh vegetation, which decreases turbulence and velocity of current in the water column and reduces resuspension by stabilising the accumulated sediment (Fagherazzi et al., 2012). Small scale fluctuation within this marsh deposit might be due to the effect of extreme events such as cyclone storms or pulses of freshwater runoff into the estuary. 
The samples in this study are located at the interface between two main domains, and the marked domain traverses the evolutionary continuum from open to closed basin settings (Fig. 9). This represents the depositional environment between an open estuary and a limited or restricted estuary. The characteristics of these samples indicate that most sediments were deposited under 'partially open to restricted estuary' conditions, which can be interpreted as the final stages of partially closed estuary evolution into marshes once the barrier structure has been fully formed. The measured organic carbon values in Fig. 5J show relatively lower values in the bottom part and this may be due to the minerogenic contribution of this marsh in the earlier stage. The gradual increasing trend of organic carbon towards the top part signifies that the organogenic component increased towards the surface compared to the minerogenic component. The superficial vegetation cover such as Porteresia coarctata, Suaeda nudiflora, Suaeda maritime, Myriostachya wightiana, and Aegialitis rotundifolia in the marshland increased the organogenic contribution in this upper part close to the surface.

\subsection{Characterizing the aerial distribution and morphology of marsh using satellite imagery}

The study of time lapses of Landsat-8 satellite images over the last two decades (Animation file 1) shows that the matured section of the marsh grew and accreted on the backside of the barrier, shielded from the open sea by the sand barrier. The area is characterized by a SW-NE wind pattern, and average wind speed increases during the humid monsoon season (Supplementary Fig. 2). This factored in the strength of the wind-generated waves during these times, which transport sediment onshore and create barriers in the tidal flat region. The strong landward directed waves with significantly high ( 3 to $5 \mathrm{~m}$ ) swell height help to transport more sediment to this barrier (Supplementary Fig. 3). Furthermore, the oblique wave action drifts the sediment from the beach's swash slope. As a result, longshore sediment transport occurs in a north-easterly direction (Fig. 2). This supply of sediment, along with the input of suspended sediment during high tidal episodes, aids in the growth of this marsh. The satellite imagery (Animation file 1) also shows that the marsh grew with time and that vegetation bloomed and increased throughout these periods. So, these hydrodynamic variations in back-barrier environmental configuration, defined by individual sedimentary sequences, are related to long-term quasistable environmental frameworks which begin to correlate with palaeo-environmental change. This signifies that the lower portion of the marsh surface is primarily under marine influence under open estuarine waters, while the upper part constrains tidal ingress to an open back-barrier lagoon. The difference between the micro-scale and the macro-scale, or the bases of knowledge on process and evolution, has been successfully bridged in this regard. Also, it is evitable that the upper saltmarsh evolution tends to follow the accretion pattern of 'sea-level rise' and the vertical growth of the marsh within the tidal frame acts as the flow velocity decreases, progressively finer particles settle to the upper part of the deposit and, hence, a predominance of suspension settlement over saltation and bed creeping transport. The upward patterns in particle size distribution may be used to provide documentation of historical response and exposure to different estuary interaction, transition factors, and thereby provide a framework for evaluating current and possibly future changes.

\subsection{Implications for management}

Page $15 / 27$ 
Coastal zones are crucial socioeconomic centres, and coastal ecosystems have suffered substantial economic, societal, and ecological destruction over decades. The understanding of the modern estuary barrier system's origins and behavior plays an important role in implementing effective coastal-zone management programs. The identification of possible estuary trajectories is important for a variety of organizations and environmental managers. The aim of this research on Chandipur marshland was to improve our understanding of the barrier estuarine regime by quantifying multivariate statistical parameters that underline the utility of geomorphology and the pattern of barrier estuarine evolution in designing computational models for coastal management. The need for recognizing historical changes, to creating baselines which will allow the present to be placed in perspective, and predicting the consequences of potential changes has been recognized at the management policy and local authority levels. This is important to ensure long-term estuarine and catchment survival, regeneration, and sustainable usage. Additionally, the understanding of the ancient barrier-lagoonal analogues within the stratigraphic record is important in designing effective sedimentary models used in the exploration for mineral resources. Further impetus has also been provided by the importance of coastal barriers and associated back barrier facies within the stratigraphic record and their relevance to the design of exploration models for hydrocarbons, coal deposits, and mineral resources.

\section{Conclusions}

The particle size data mainly represents changing hydrodynamics in the back barrier region, providing considerable insight into the meso scale behavior of the barrier estuary system with the $\sim 1.2 \mathrm{~m}$ of sediment record at high resolution over the past decades. The bivariate contour plots are used effectively for the analysis of variations in the back-barrier area. These grain size distributions with multivariate statistics do offer useful tools to analyze the clastic sedimentary depositional system. Composition data analysis combined with PCA and CA has helped us to understand the various conditions of the ecosystem and depositional cycles in the deposit. In addition, the textural parameters can be used as direct variants of the hydrodynamic responses and as proxies for differentiating various sedimentary environments or depositional sub-environments of various spatial and temporal scales. However, since it does not specifically describe the type of sedimentary environment that may have a role in determining the composition of grain size data, statistical analysis is used in conjunction with total organic carbon for a better understanding of the deposition environment of the back barrier marsh.

\section{Declaration Of Competing Interest}

The authors declare that the study reported in this paper does not have known conflicting financial interests or personal partnerships.

\section{Acknowledgements}

KS sincerely acknowledges the Department of Geology, University of North Bengal, and University of Calcutta for their valuable assistance and encouragement. KS appreciates the financial support provided 
by project proposal 1970/R-2019 to complete this work. Swarnadwip Saha (Researcher of IISER-Kolkata) and the villagers of Chandipur are thanked for their assistance during the fieldwork.

\section{References}

1. Allen J (1990) The Severn Estuary in southwest Britain: its retreat under marine transgression, and fine-sediment regime. Sed Geol 66:13-28

2. Allen $J$ (1992) Large-scale textural patterns and sedimentary processes on tidal salt marshes in the Severn Estuary, southwest Britain. Sed Geol 81:299-318

3. Allen J, Haslett S (2002) Buried salt-marsh edges and tide-level cycles in the mid-Holocene of the Caldicot Level (Gwent), South Wales, UK. The Holocene 12:303-324

4. Allen JR (2004) Annual textural banding in Holocene estuarine silts, Severn Estuary Levels (SW Britain): patterns, cause and implications. The Holocene 14:536-552

5. Allen JR, Haslett SK (2006) Granulometric characterization and evaluation of annually banded midHolocene estuarine silts, Welsh Severn Estuary (UK): coastal change, sea level and climate. Q Sci Rev 25:1418-1446

6. Alsharhan A, El-Sammak A (2004) Grain-size analysis and characterization of sedimentary environments of the United Arab Emirates coastal area.Journal of coastal Research:464-477

7. Bandyopadhyay S, Ghosh PK, Jana NC, Sinha S (2016) Probability of flooding and vulnerability assessment in the Ajay River, Eastern India: implications for mitigation. Environ Earth Sci 75:578

8. Barbier EB, Hacker SD, Kennedy C, Koch EW, Stier AC, Silliman BR (2011) The value of estuarine and coastal ecosystem services. Ecol Monogr 81:169-193

9. Beierle BD, Lamoureux SF, Cockburn JM, Spooner I (2002) A new method for visualizing sediment particle size distributions. J Paleolimnol 27:279-283

10. Bengtsson L, Enell M (1986) Chemical analysis.. In: In: Berglund BE (ed) Handbook of Holocene Palaeoecology and Palaeohydrology. John Wiley \& Sons Ltd, Chichester-pp

11. Blott SJ, Pye K (2001) GRADISTAT: a grain size distribution and statistics package for the analysis of unconsolidated sediments. Earth Surf Proc Land 26:1237-1248

12. Brevik EC, Homburg JA (2004) A 5000 year record of carbon sequestration from a coastal lagoon and wetland complex, Southern California, USA. CATENA 57:221-232

13. Carver RE (1971) Procedures in sedimentary petrology. John Wiley \& Sons Incorporated

14. Chang TS, Flemming BW, Bartholomä A (2007) Distinction between sortable silts and aggregated particles in muddy intertidal sediments of the East Frisian Wadden Sea, southern North Sea. Sed Geol 202:453-463

15. Chen B, Xiao X, Li X, Pan L, Doughty R, Ma J, Dong J, Qin Y, Zhao B, Wu Z (2017) A mangrove forest map of China in 2015: Analysis of time series Landsat 7/8 and Sentinel-1A imagery in Google Earth Engine cloud computing platform. ISPRS Journal of Photogrammetry and Remote Sensing 131:104-120 
16. Clarke DW, Boyle JF, Chiverrell RC, Lario J, Plater AJ (2014) A sediment record of barrier estuary behaviour at the mesoscale: Interpreting high-resolution particle size analysis. Geomorphology 221:51-68

17. Cooper J, McKenna J (2008) Working with natural processes: the challenge for coastal protection strategies. Geogr J 174:315-331

18. Cooper J, McKenna J, Jackson D, O'Connor M (2007) Mesoscale coastal behavior related to morphological self-adjustment. Geology 35:187-190

19. Cooper JAG (2013) Mesoscale geomorphic change on low energy barrier islands in Chesapeake Bay, USA. Geomorphology 199:82-94

20. Cooper JAG, Green AN, Loureiro C (2018) Geological constraints on mesoscale coastal barrier behaviour. Glob Planet Change 168:15-34

21. Creel L (2003) Ripple effects: population and coastal regions. Population Reference Bureau Washington, DC

22. Dark P, Allen JRL (2005) Seasonal deposition of Holocene banded sediments in the Severn Estuary Levels (southwest Britain): palynological and sedimentological evidence. Q Sci Rev 24:11-33

23. Donato S, Reinhardt E, Boyce J, Pilarczyk J, Jupp B (2009) Particle-size distribution of inferred tsunami deposits in Sur Lagoon, Sultanate of Oman. Mar Geol 257:54-64

24. Emery KO (1961) A simple method of measuring beach profiles. Limnol Oceanogr 6:90-93

25. Fagherazzi S, Kirwan ML, Mudd SM, Guntenspergen GR, Temmerman S, D'Alpaos A, Van De Koppel J, Rybczyk JM, Reyes E, Craft C (2012) Numerical models of salt marsh evolution: Ecological, geomorphic, and climatic factors.Reviews of Geophysics50

26. FitzGerald DM, Fenster MS, Argow BA, Buynevich IV (2008) Coastal impacts due to sea-level rise.Annual Review of Earth and Planetary Sciences 36

27. Flood R, Barr I, Weltje GJ, Roberson S, Russell M, Meneely J, Orford J (2018) Provenance and depositional variability of the thin mud facies in the lower Ganges-Brahmaputra delta, West Bengal Sundarbans, India. Mar Geol 395:198-218

28. Flood R, Bloemsma M, Weltje GJ, Barr I, O'Rourke S, Turner J, Orford J (2016) Compositional data analysis of Holocene sediments from the West Bengal Sundarbans, India: geochemical proxies for grain-size variability in a delta environment. Appl Geochem 75:222-235

29. Flood R, Orford J, McKinley J, Roberson S (2015) Effective grain size distribution analysis for interpretation of tidal-deltaic facies: West Bengal Sundarbans. Sed Geol 318:58-74

30. French J, Burningham H (2009) Coastal geomorphology: trends and challenges. Prog Phys Geogr 33:117-129

31. French J, Payo A, Murray B, Orford J, Eliot M, Cowell P (2016) Appropriate complexity for the prediction of coastal and estuarine geomorphic behaviour at decadal to centennial scales. Geomorphology 256:3-16 
32. Gedan KB, Kirwan ML, Wolanski E, Barbier EB, Silliman BR (2011) The present and future role of coastal wetland vegetation in protecting shorelines: answering recent challenges to the paradigm. Clim Change 106:7-29

33. Goudie A (2013) Characterising the distribution and morphology of creeks and pans on salt marshes in England and Wales using Google Earth. Estuarine, Coastal and Shelf Science 129:112-123

34. He C, Bartholdy J, Christiansen C (2012) Clay mineralogy, grain size distribution and their correlations with trace metals in the salt marsh sediments of the Skallingen barrier spit, Danish Wadden Sea. Environ Earth Sci 67:759-769

35. Heap AD, Bryce S, Ryan DA (2004) Facies evolution of Holocene estuaries and deltas: a large-sample statistical study from Australia. Sed Geol 168:1-17

36. Heiri O, Lotter AF, Lemcke G (2001) Loss on ignition as a method for estimating organic and carbonate content in sediments: reproducibility and comparability of results. J Paleolimnol 25:101110

37. Houben P (2007) Geomorphological facies reconstruction of Late Quaternary alluvia by the application of fluvial architecture concepts. Geomorphology 86:94-114

38. Jennings S, Carter R, Orford J (1993) Late Holocene salt marsh development under a regime of rapid relative-sea-level rise: Chezzetcook Inlet, Nova Scotia. Implications for the interpretation of palaeomarsh sequences. Can J Earth Sci 30:1374-1384

39. Kanhaiya S, Singh B, Tripathi M, Sahu S, Tiwari V (2017) Lithofacies and particle-size characteristics of late Quaternary floodplain deposits along the middle reaches of the Ganga river, central Ganga plain, India. Geomorphology 284:220-228

40. Klein RJ, Nicholls RJ (1999) Assessment of coastal vulnerability to climate change. Ambio:182-187

41. Klein RJ, Smit MJ, Goosen H, Hulsbergen CH (1998) Resilience and vulnerability: coastal dynamics or Dutch dikes?Geographical Journal:259-268

42. Ladd CJ, Duggan-Edwards MF, Bouma TJ, Pagès JF, Skov MW (2019) Sediment supply explains long-term and large-scale patterns in salt marsh lateral expansion and erosion. Geophys Res Lett 46:11178-11187

43. Lario J, Spencer C, Plater A, Zazo C, Goy J, Dabrio CJ (2002) Particle size characterisation of Holocene back-barrier sequences from North Atlantic coasts (SW Spain and SE England). Geomorphology 42:25-42

44. Leonardi N, Carnacina I, Donatelli C, Ganju NK, Plater AJ, Schuerch M, Temmerman S (2018) Dynamic interactions between coastal storms and salt marshes: A review. Geomorphology 301:92107

45. Liang J, Gong J, Li W (2018) Applications and impacts of Google Earth: A decadal review (20062016). ISPRS Journal of Photogrammetry and Remote Sensing 146:91-107

46. Mcleod E, Chmura GL, Bouillon S, Salm R, Björk M, Duarte CM, Lovelock CE, Schlesinger WH, Silliman BR (2011) A blueprint for blue carbon: toward an improved understanding of the role of vegetated coastal habitats in sequestering CO2. Front Ecol Environ 9:552-560 
47. Mishra PK, Parth S, Ankit Y, Kumar S, Ambili V, Kumar VV, Singh S, Anoop A (2019) Geochemical and sedimentological characteristics of surface sediments from Ashtamudi Estuary, Southern India: implications for provenance and modern sedimentary dynamics. Environ Earth Sci 78:395

48. Molinaroli E, Guerzoni S, De Falco G, Sarretta A, Cucco A, Como S, Simeone S, Perilli A, Magni P (2009) Relationships between hydrodynamic parameters and grain size in two contrasting transitional environments: The Lagoons of Venice and Cabras, Italy. Sed Geol 219:196-207

49. Möller I (2006) Quantifying saltmarsh vegetation and its effect on wave height dissipation: Results from a UK East coast saltmarsh. Estuarine, Coastal and Shelf Science 69:337-351

50. Morris JT, Sundareshwar P, Nietch CT, Kjerfve B, Cahoon DR (2002) Responses of coastal wetlands to rising sea level. Ecology 83:2869-2877

51. Mudd SM, Fagherazzi S, Morris JT, Furbish DJ (2004) Flow, sedimentation, and biomass production on a vegetated salt marsh in South Carolina: toward a predictive model of marsh morphologic and ecologic evolution. The Ecogeomorphology of Tidal Marshes, Coastal Estuarine Stud 59:165-187

52. Nordstrom KF, Jackson NL, Rader AM, Garilao ES (2018) Protecting natural landforms and habitats by nourishing an eroding estuarine beach. Environ Earth Sci 77:1-14

53. Oost A, Hoekstra P, Wiersma A, Flemming B, Lammerts E, Pejrup M, Hofstede J, Van der Valk B, Kiden $P$, Bartholdy J (2012) Barrier island management: Lessons from the past and directions for the future. Ocean \& Coastal Management 68:18-38

54. Orford J, Carter R, McKenna J, Jennings S (1995) The relationship between the rate of mesoscale sea-level rise and the rate of retreat of swash-aligned gravel-dominated barriers. Mar Geol 124:177186

55. Panwar S, Chakrapani G (2016) Seasonal variability of grain size, weathering intensity, and provenance of channel sediments in the Alaknanda River Basin, an upstream of river Ganga, India. Environ Earth Sci 75:998

56. Pethick J (1981) Long-term accretion rates on tidal salt marshes. J Sediment Res 51:571-577

57. Pilkey OH, Cooper JAG, Lewis DA (2009) Global distribution and geomorphology of fetch-limited barrier islands.Journal of Coastal Research:819-929

58. Purkait B, Majumdar DD (2014) Distinguishing different sedimentary facies in a deltaic system. Sed Geol 308:53-62

59. Puy A, Herzog M, Escriche P, Marouche A, Oubana Y, Bubenzer O (2018) Detection of sand encroachment patterns in desert oases. The case of Erg Chebbi (Morocco). Sci Total Environ 642:241-249

60. Rahman R, Plater AJ (2014) Particle-size evidence of estuary evolution: a rapid and diagnostic tool for determining the nature of recent saltmarsh accretion. Geomorphology 213:139-152

61. Reed DJ (1995) The response of coastal marshes to sea-level rise: Survival or submergence? Earth Surf Proc Land 20:39-48

62. Roy PS (1994) Holocene estuary evolution-stratigraphic studies from southeastern Australia 
63. Sathish S, Kankara R, Selvan SC, Umamaheswari M, Rasheed K (2018) Wave-beach sediment interaction with shoreline changes along a headland bounded pocket beach, West coast of India. Environ Earth Sci 77:1-12

64. Seager R, Vecchi GA (2010) Greenhouse warming and the 21 st century hydroclimate of southwestern North America. Proceedings of the National Academy of Sciences 107:21277-21282

65. Shennan I, Bradley S, Milne G, Brooks A, Bassett S, Hamilton S (2006) Relative sea-level changes, glacial isostatic modelling and ice-sheet reconstructions from the British Isles since the Last Glacial Maximum. Journal of Quaternary Science: Published for the Quaternary Research Association 21:585-599

66. Spencer T, Möller I, Rupprecht F, Bouma T, Van Wesenbeeck B, Kudella M, Paul M, Jensen K, Wolters G, Miranda-Lange M (2016) Salt marsh surface survives true-to-scale simulated storm surges. Earth Surf Proc Land 41:543-552

67. Stupples P, Plater A (2007) Statistical analysis of the temporal and spatial controls on tidal signal preservation in late-Holocene tidal rhythmites, Romney Marsh, Southeast England. Int J Earth Sci 96:957-976

68. Stutz ML, Pilkey OH (2011) Open-ocean barrier islands: global influence of climatic, oceanographic, and depositional settings. J Coastal Res 27:207-222

69. Switzer AD, Pucillo K, Haredy RA, Jones BG, Bryant EA (2005) Sea level, storm, or tsunami: enigmatic sand sheet deposits in a sheltered coastal embayment from southeastern New South Wales, Australia. J Coastal Res 21:655-663

70. Su Q, Peng C, Yi L, Huang H, Liu Y, Xu X, Chen G, Yu H (2016) An improved method of sediment grain size trend analysis in the Xiaoqinghe Estuary, southwestern Laizhou Bay, China. Environ Earth Sci 75:1-10

71. Tang Y, Zheng Z, Chen C, Wang M, Chen B (2018) Evolution of the Lian River coastal basin in response to Quaternary marine transgressions in Southeast China. Sed Geol 366:1-13

72. Van Wijnen H, Bakker J (2001) Long-term surface elevation change in salt marshes: a prediction of marsh response to future sea-level rise. Estuar Coast Shelf Sci 52:381-390

73. Walker RG (1992) Facies, facies models and modern stratigraphic concepts. Facies models response to sea-level change:1-14

74. Yu J, Li Y, Han G, Zhou D, Fu Y, Guan B, Wang G, Ning K, Wu H, Wang J (2014) The spatial distribution characteristics of soil salinity in coastal zone of the Yellow River Delta. Environ Earth Sci 72:589599

75. Zubillaga JJK, Edwards AC (2005) Grain size discrimination between sands of desert and coastal dunes from northwestern Mexico. Revista Mexicana de Ciencias Geológicas 22:383-390

\section{Figures}




\section{Figure 1}

Location of study site in Chandipur marsh and location of transects (white dotted line C1-C90) showing sample sites within the marsh sediment. Retrieving of the subsurface sediment profile was carried out by making a trench at CT location.

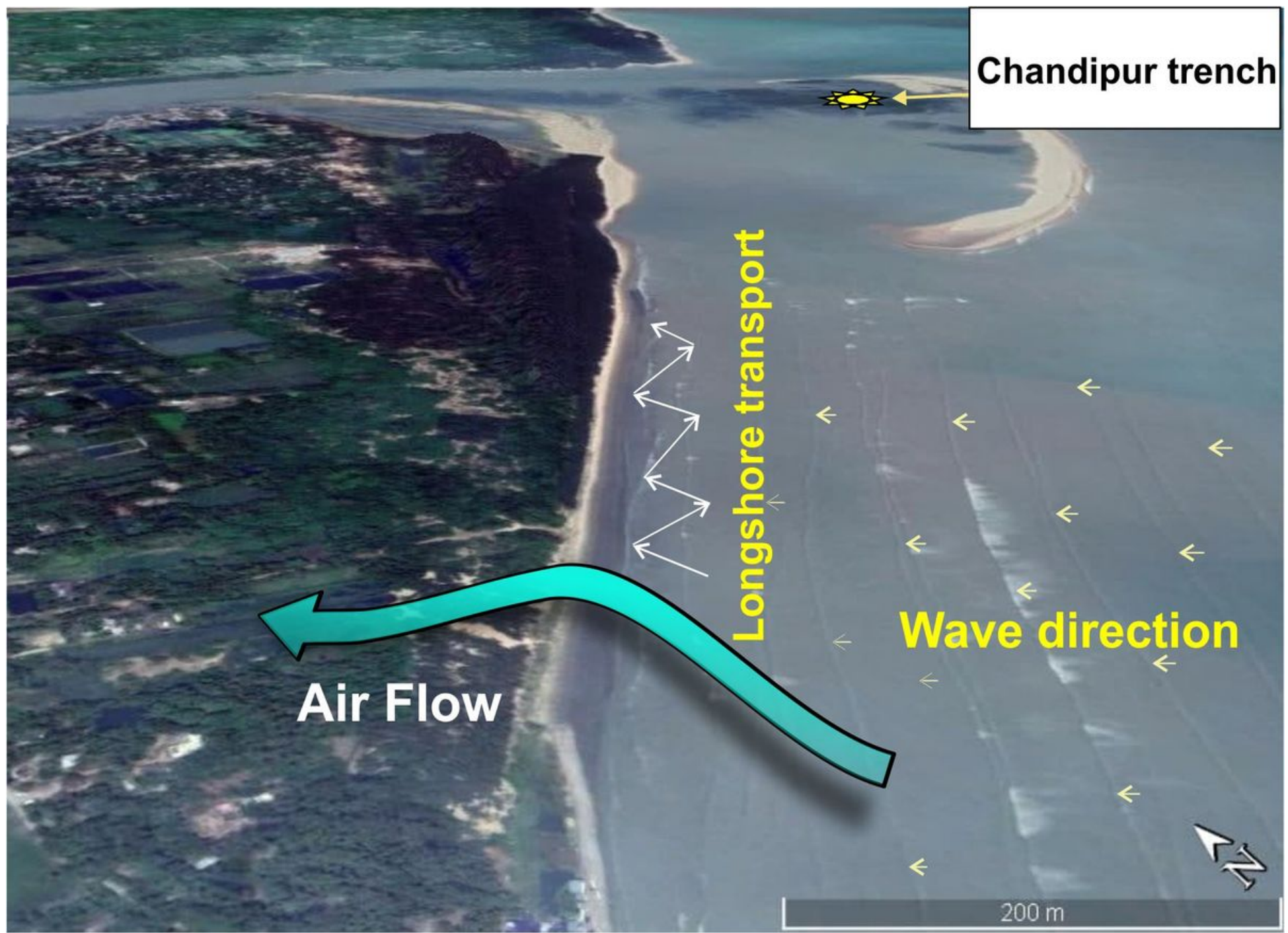

\section{Figure 2}

The oblique aerial view of the Chandipur coastal region shows the orientations of waves on the seashore (small solid arrow), near-surface wind flows (big bold blue solid arrow) and longshore sediment transport direction (medium white arrow) of the area. 


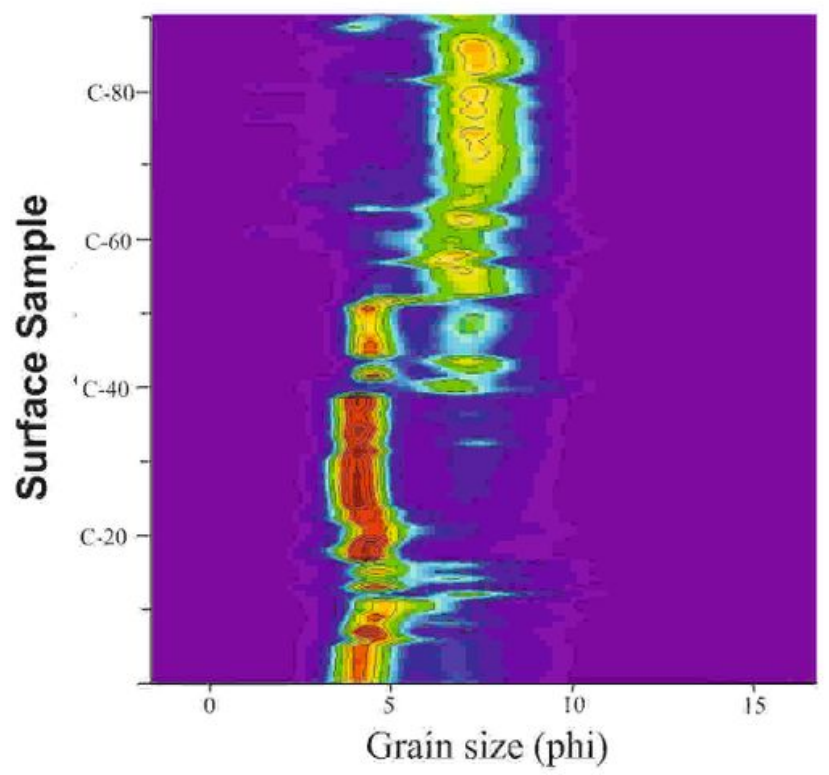

(A)

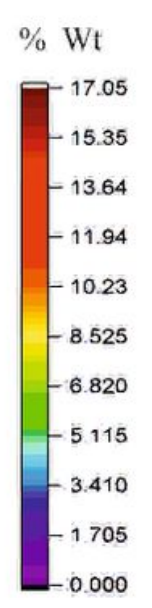

CT-117 0

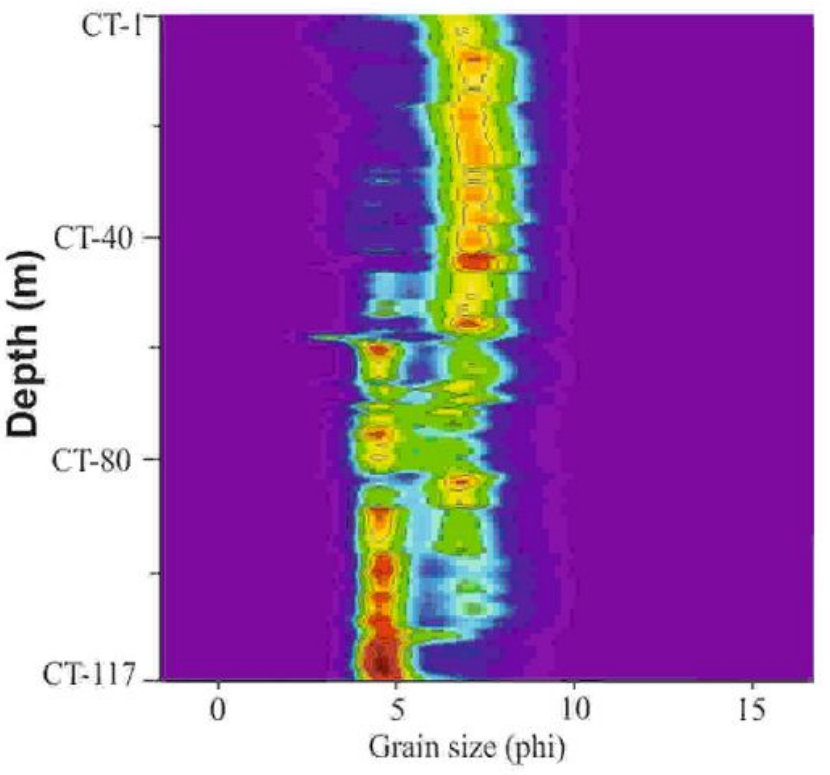

(B)

\section{Figure 3}

Showing particle size distribution with surface contour plots of surface sediment transect (A) and subsurface sediment profile (B). 

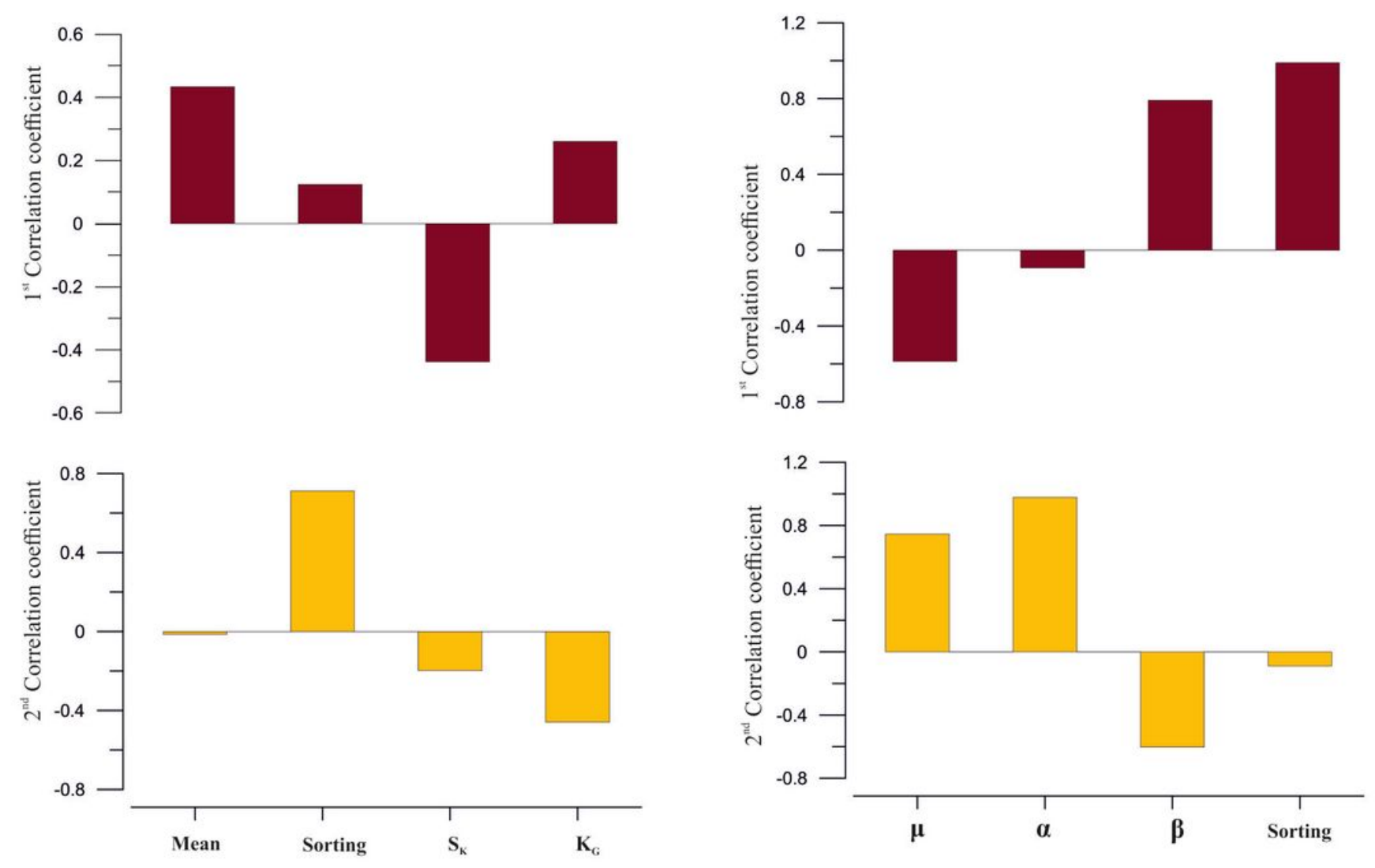

(A)

(B)

\section{Figure 4}

Two main principal component loadings for each grain size class of each log-normal and of log skewLaplace coefficient of the subsurface CT sample GSD. 


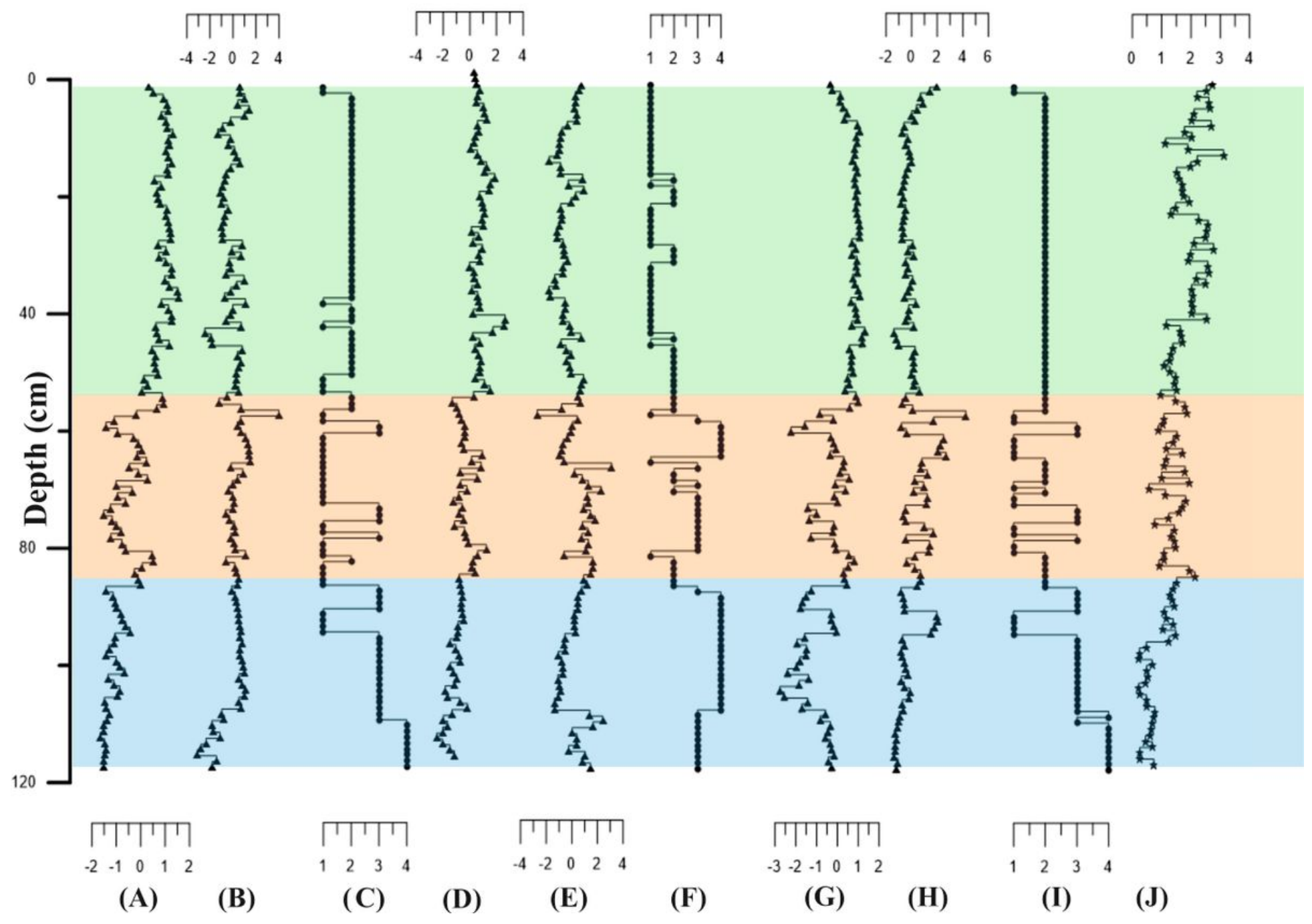

Figure 5

Diagrams 5A and 5B show PCA score plots for the first and second principal components of the lognormal coefficients. PCA score plots for the first (5D) and second (5E) principal components of the log skew-Laplace coefficients are also shown. Graphs $5 \mathrm{C}$ and $5 \mathrm{~F}$ show the vertical disposition of the broad stratigraphical facies throughout the $\mathrm{CT}$ sample, derived from the clustering analysis with the model coefficients. PCA score plots for the first (5G) and second (5H) principal components of the clrtransformed subsurface CT sample are also shown. The vertical disposition of the broad stratigraphical facies throughout the clr-transformed subsurface sample GSD data is given in 5 I. The measured organic carbon in the marsh is plotted in $5 \mathrm{~J}$.

Figure 6 
The main cluster group association of log-normal (6A) and log skew-Laplace (6B) coefficient of the subsurface CT sample is shown in the two biplot.
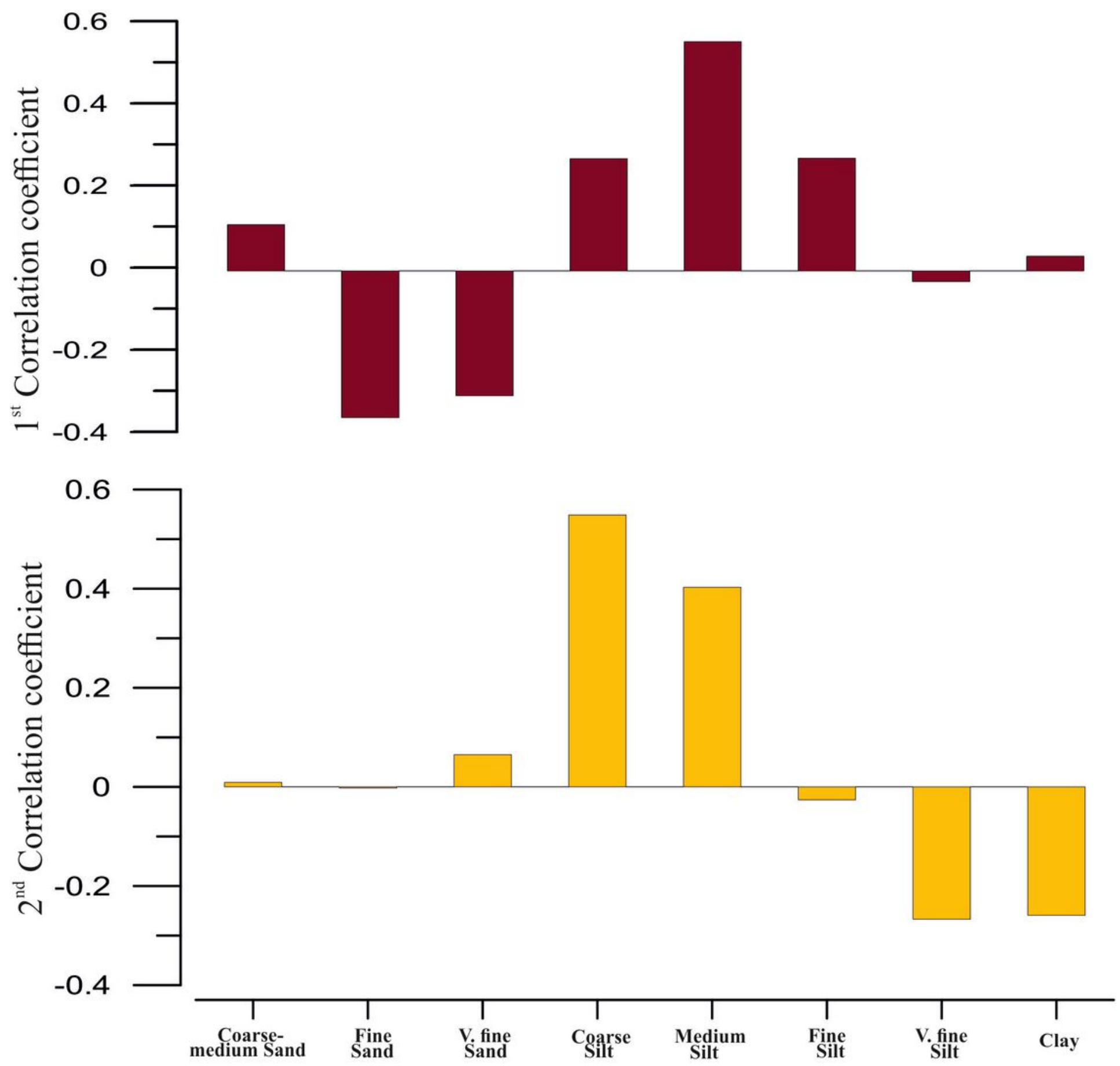

Figure 7

First (a) and second (b) principal component loadings for each grain size class of the clr-transformed subsurface CT sample GSD. 


\section{Figure 8}

Biplot of principal components with cluster group association of clr-transformed subsurface CT sample GSD.

\section{Figure 9}

Bivariate plots of grain size parameters of subsurface sediment samples plotted against the domains of Tanner (1991a; 1991b), Lario et al. (2002).

\section{Supplementary Files}

This is a list of supplementary files associated with this preprint. Click to download.

- Animation1chandipurTimelapseLandsat8.mp4

- Animationfile.docx

- Supplimentaryfigures.docx 